\title{
Efektivitas Pemberian Alokasi Kamar pada Biro Perjalanan Wisata: Studi Kasus Hotel The Kuta Beach Heritage Bali
}

\author{
Danny Martin'1, Ida Ayu Sri Puspa Adi*2, Putu Ayu Ariasih³ \\ 1,3 Program Studi Manajemen Bisnis Perjalanan, Politeknik Pariwisata Bali \\ Jl. Darmawangsa, Kampial, Kuta Selatan, Badung, Bali \\ 2Program Studi Manajemen Divisi Kamar, Politeknik Pariwisata Bali \\ Jl. Darmawangsa, Kampial, Kuta Selatan, Badung, Bali \\ 1dmzhang22@gmail.com, 2* puspa.adi@ppb.ac.id, 3ayuaryasih@ppb.ac.id \\ *Corresponding author
}

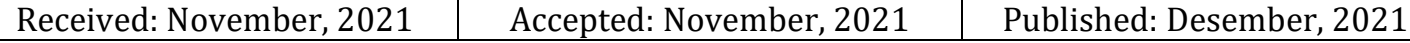

\begin{abstract}
Despite the rapid development of online travel agents who market hotel rooms via the internet, traditional travel agencies also still play an important role in marketing and booking hotel rooms. As The Kuta Beach Heritage hotel still utilizes and uses room marketing channels through offline travel agencies. This study aims to determine the effectiveness of providing room allocation or room allocation to travel agents at The Kuta Beach Heritage Bali. The data used is secondary data in the form of production from each travel agency and given room allocation. While the primary data was obtained through interviews with various related parties at the hotel. Data were analysed quantitatively and qualitatively. The results showed that the utilization of room allocation by the travel agency had not been maximized or had not been able to achieve the target given by the hotel, which was $60 \%$. The practical implication of this research is the need for innovative efforts to increase the production of room nights by both hotels and travel agencies
\end{abstract}

Keywords: room allotment, travel agency, room night, accommodation

\begin{abstract}
Abstrak
Di balik pesatnya tbiro perjalanan online yang memasarkan kamar hotel melalui internet, biro perjalanan wisata tradisional juga masih berperan penting dalam pemasaran dan pemesanan kamar hotel. Sebagaimana hotel The Kuta Beach Heritage masih memanfaatkan dan menggunakan saluran pemasaran kamar melalui biro perjalanan wisata offline. Penelitian ini bertujuan untuk mengetahui efektivitas pemberian alokasi kamar atau alokasi kamar kepada biro perjalanan wisata di The Kuta Beach Heritage Bali. Data yang digunakan adalah data sekunder berupa produksi dari masing-masing biro perjalanan dan room allotment yang diberikan. Sedangkan data primer diperoleh melalui wawancara kepada berbagai pihak terkait di hotel. Data dianalisis secara kuantitatif dan kualitatif. Hasil penelitian menunjukkan bahwa pemanfaat alokasi kamar oleh biro perjalanan wisata belum maksimal atau belum mampu mencapai target yang diberikan oleh pihak hotel yaitu sebesar $60 \%$. Implikasi praktis dari peneitian ini adalah perlunya usaha-usaha inovatif
\end{abstract}


Efektivitas Pemberian Alokasi Kamar pada Biro Perjalanan Wisata: Kasus di Hotel The Kuta Beach Heritage Bali

Denny Martin, Ida Ayu Sri Puspa Adi, Putu Ayu Aryasih

untuk meningkatkan produksi room night baik oleh pihak hotel maupun biro perjalanan wisata.

Kata kunci: room allotment, travel agent, room night,

\section{PENDAHULUAN}

Terdapat banyak factor yang memengaruhi keberhasilan sebuah usaha pariwisata termasuk hotel dalam mencapai targetnya. Faktor yang dominan yang banyak diteliti adalah kepuasan wisatawan (Febriyana, Suprastayasa, \& Darmiati, 2020). Berbagai praktik manajemen pendapatan modern telah diimplementasikan ke dalam industri hotel pada 1990-an dalam upaya untuk menyediakan hotel dan resor dengan profitabilitas yang lebih besar. Seiring dengan perbaikan yang dilakukan pada praktik tersebut, peran manajer pendapatan hotel berkembang untuk memenuhi berbagai perubahan ini. Telah terjadi perubahan besar dalam praktik dan tanggung jawab manajer pendapatan hotel (Ferguson \& Smith, 2014). Suastini (2019) misalnya meneliti strategi harga wholesale meningkatkan pandapatan kamar. Salah satu strategi yang mendapatkan perhatian adalah bagaiaman manajer hotel mengatur alokasi kamar agar pendapatan yang diterima menjadi maksimal.

The Kuta Beach Heritage Hotel adalah hotel bintang 5 yang berlokasi di depan pantai Kuta dengan total jumlah 159 kamar. Antara hotel ini dengan hotel lainnya yang berada di daerah pantai Kuta memiliki tingkat persaingan yang sangat tinggi untuk mendapatkan wisatawan untuk menginap di hotel secara maksimal. Dalam persaingan yang ketat, tingkat hunian kamar di hotel ini relative tinggi dengan tingkat hunian tertinggi pada tahun 2019 sebesar 85,99\% atau sebanyak 49.318 room night. Tingkat hunian kamar terendah terjadi pada tahun 2018 sebesar 78,54\% atau sebanyak 44,827 room night terjual. Persentase rata-rata kamar terjual selama 5 tahun terakhir dari tahun 2015 hingga tahun 2019 adalah sebesar 81,46\% atau sebanyak 231,573 room night terjual.

Dalam meningkatkan tingkat hunian kamar, departmen sales marketing berperan penting dengan memasarkan dan memperkenalkan produk hotel secara Business to Business maupun Business to Customers. Selain kebijakan penentuan strategi penjualan, hal yang perlu diperhatikan adalah alokasi pemberian room allotment kepada biro perjalanan wisata yang memiliki kontrak kerjasama dengan pihak hotel, dimana peran biro perjalanan wisata sebagai mediator dengan konsumen yaitu membantu kegiatan penjualan dan pemasaran. Pihak hotel memberikan alokasi kamar/room allotment kepada biro perjalanan wisata bertujuan untuk dipasarkan kembali kepada konsumen oleh pihak biro perjalanan wisata. Pemberian alokasi kamar bertujuan sebagai guarantee pihak hotel kepada pihak biro perjalanan wisata bahwa saat pihak biro perjalanan wisata akan melakukan pemesanan, kamar hotel dipastikan masih tersedia.

Efektivitas pemberian allotment dari pihak hotel kepada biro perjalanan wisata berpengaruh kepada tujuan management untuk mendapatkan tingkat penjualan kamar hotel secara maksimal.

Total alokasi room allotment tersedia dari hotel kepada biro perjalanan wisata selama 5 tahun adalah sebesar 46,355 room night, sedangkan penjualan kamar yang diproduksi oleh biro perjalanan wisata adalah sebesar 19,171, terdapat selisih total kamar 27,184 yang tidak terjual. Realisasi tingkat penjualan biro perjalanan wisata terhadap alokasi room allotment yang telah diberikan pihak hotel belum maksimal dari tahun 2015 hingga tahun 2019. Dari hasil wawancara dengan bagian sales \& marketing hotel diketahui bahwa target realisasi room allotment yang diharapkan oleh hotel kepada biro perjalanan wisata adalah $60 \%$ dari jatah yang telah diberikan. Namun demikian terdapat kesenjangan dari produksi room night yang diberikan biro perjalanan wisata, dengan 
tujuan manajemen hotel untuk mencapai tingkat penjualan kamar secara maksimal yaitu sebesar 100\% occupancy atau sebesar 159 kamar terjual secara habis setiap tahun

Pengelolaan room allotment merupakan salah satu cara hotel dalam merancang dan meningkatkan hunian kamar (Rama et al. 2019). Oleh karena itu tujuan dari penelitian ini adalah menemukenali bagaimanakah efektivitas pemberian alokasi kamar kepada biro perjalanan wisata di hotel The Kuta Beach Heritage Bali.

\section{METODE PENELITIAN}

Penelitian ini dilaksanakan di Hotel The Kuta Beach Heritage Bali, yang beralamat di Jalan Pantai Kuta, Kabupaten Badung, Bali. Dalam penelitian ini digunakan 2 jenis data, yaitu data kuantitatif dan data kualitatif. Sedangkan jenis data yang digunakan adalah data primer dan data sekunder.

Pengumpulan data dilakukan melalui studi dokumentasi dan wawancara. Dokumen primer didapatkan langsung dari sumber utama yaitu Opera property management system dari Hotel The Kuta Beach Heritage Bali. Penulis melakukan wawancara kepada pihak terkait di hotel, yaitu sales marketing manajer dan staff untuk mendapatkan informasi-informasi yang diperlukan dalam penelitian ini.

Penelitian ini menggunakan pendekatan mix methods, yaitu metode yang menggabungkan antara metode kuantitatif dan metode kualitatif. Terdapat dua model dalam penelitian mix methods, menurut Sugiyono (2018) yaitu sequential (berurutan) dan concurrent (campuran). Model sequential adalah suatu prosedur penelitian dimana peneliti menggabungkan hasil penelitian dari satu metode ke metode yang lain. Penggabungan metode ini menurut Sugiyono (2018) dilakukan secara berurutan dalam waktu yang berbeda, sedangkan dalam tipe concurrent penggabungan dengan cara dicampur dalam waktu yang sama. Penelitian ini menggunakan model mix methods yaitu model sequential dengan menggunakan pendekatan explanatory, yaitu data dianalisis secara kuantitatif pada tahap pertama yaitu untuk mengetahui efektivitas room allotment, dan diikuti pengumpulan dan analisis data kualitatif pada tahap ke dua.

\section{HASIL DAN PEMBAHAN}

\subsection{Paparan Data}

Hotel The Kuta Beach Heritage memberikan room allotment kepada biro perjalanan wisata dengan jumlah yang berbeda-beda sesuai dengan berbagai pertimbangan yang telah dilakukan sebelumnya. Tabel 1 berikut menunjukkan alokasi room allotment yang diberikan kepada biro perjalanan wisata di hotel The Kuta Beach Heritage

Tabel1: Room Allotment BPW pada Hotel The Kuta Beach Heritage Bali, 2015-2019

[Sumber : Department Sales Marketing Hotel The Kuta Beach Heritage Bali, 2020]

\begin{tabular}{llrrrrrr}
\hline & Biro Perjalanan wisata & \multicolumn{7}{c}{ Room Allotment } & \multirow{2}{*}{ Total } \\
\cline { 3 - 7 } & & 2015 & 2016 & 2017 & 2018 & 2019 & 4015 \\
\hline 1. & K Tours \& Travel & 1095 & 1095 & 1095 & 365 & 365 & 10220 \\
2. & G Travel Association. & 730 & 1825 & 1825 & 2920 & 2920 & 8395 \\
3. & M. G. H. & 1825 & 1825 & 1825 & 1825 & 1095 & 4015 \\
4. & M. A. & 1095 & 1095 & 1095 & 365 & 365 & 12410 \\
5. & P. W. & 1825 & 1825 & 2920 & 2920 & 2920 & 4015 \\
6. & H. Tours \& Travel. & 1095 & 1095 & 1095 & 365 & 365 & 1460 \\
7. & A.W. & 0 & 365 & 365 & 365 & 365 & 1825 \\
8. & G. V. & 365 & 365 & 365 & 365 & 365 & \\
\hline
\end{tabular}


Room allotment yang diberikan oleh hotel The Kuta Beach Heritage mengalami kenaikan dari tahun 2015 hingga 2017 dari 8030 room allotment menjadi 10585 room allotment. Akan tetapi dari tahun 2017 hingga 2019 terjadi penurunan alokasi kamar dari 10585 menjadi 8760 room allotment terhadap 8 biro perjalanan wisata yang memiliki kerjasama dengan hotel tersebut. Biro perjalanan tersebut tidak sepenuhnya mampu menghabisan alokasi kamar yang diberikan sebagaimana terlihat pada table 2 yaitu produksi room night dari biro perjalanan wisata di hotel The Kuta Beach Heritage.

Tabel 2: Produksi Room Night BPW di Hotel The Kuta Beach Heritage 2015-2019

[Sumber : Department Sales Marketing Hotel The Kuta Beach Heritage Bali, 2020]

\begin{tabular}{|c|c|c|c|c|c|c|c|}
\hline \multirow[t]{2}{*}{ No } & \multirow[t]{2}{*}{ Biro Perjalanan Wisata } & \multicolumn{5}{|c|}{ Produksi Room Night } & \multirow[t]{2}{*}{ Total } \\
\hline & & 2015 & 2016 & 2017 & 2018 & 2019 & \\
\hline 1 & K Tours \& Travel & 796 & 399 & 278 & 190 & 130 & 1793 \\
\hline 2 & G Travel Association. & 46 & 720 & 1330 & 2575 & 2293 & 6964 \\
\hline 3 & M. G. H. & 802 & 480 & 750 & 414 & 432 & 2878 \\
\hline 4 & M. A. & 665 & 265 & 248 & 81 & 77 & 1336 \\
\hline 5 & P.W. & 247 & 886 & 1550 & 1273 & 1108 & 5064 \\
\hline 6 & H. Tours \& Travel. & 295 & 191 & 202 & 75 & 57 & 820 \\
\hline 7 & A.W. & 0 & 95 & 56 & 53 & 17 & 221 \\
\hline 8 & G.V. & 8 & 37 & 45 & 0 & 5 & 95 \\
\hline
\end{tabular}

Produksi room night dari biro perjalanan wisata pada tahun 2015 hingga 2018 mengalami kenaikan setiap tahun dari 2859 room night di tahun 2015 hingga 4661 room night pada tahun 2018. Pada tahun 2019 terjadi penurunan produksi biro perjalanan wisata akan tetapi tidak signifikan. Hotel The Kuta Beach Heritage sebenarnya juga memiliki minimum target pencapaian dari jumlah allotment yang telah diberikan kepada biro perjalanan wisata yaitu minimal 60\%. Berikut adalah perbandingan antara jumlah allotment yang telah diberikan, produksi room night biro perjalanan wisata, dan target minimum yang harus dicapai biro perjalanan wisata selama 5 tahun yaitu dari tahun 2015 hingga 2019.

Tabel 3: Target Production Hotel The Kuta Beach Heritage Bali 2015-2019

\begin{tabular}{llrrr}
\hline No & Biro Perjalanan Wisata & $\begin{array}{c}\text { Total allotment } \\
\text { (Room Night) }\end{array}$ & $\begin{array}{c}\text { Target } \\
60 \%\end{array}$ & $\begin{array}{c}\text { Realisasi } \\
\text { (Room Night) }\end{array}$ \\
\hline 1. & K Tours \& Travel & 4015 & 2409 & 1793 \\
2. & G Travel Association. & 10220 & 6132 & 6964 \\
3. & M. G. H. & 8395 & 5037 & 2878 \\
4. & M. A. & 4015 & 2409 & 1336 \\
5. & P. W. & 12410 & 7446 & 5064 \\
6. & H. Tours \& Travel. & 4015 & 2409 & 820 \\
7. & A.W. & 1460 & 876 & 221 \\
8. & G. V. & 1825 & 1095 & 95 \\
\hline
\end{tabular}

Biro perjalanan wisata P. W. memiliki total jumlah room allotment paling besar, dan diikuti di urutan kedua oleh Gulliver Travel Associates dengan jumlah produksi room night dua terbesar. Sedangkan room allotment yang diberikan paling rendah terdapat pada biro perjalanan wisata G.V. dengan jumlah produksi room night terkecil.

Untuk mengukur efektivitas alokasi room allotment kepada biro perjalanan wisata di hotel The Kuta Beach Heritage Bali, sebagaimana disampaikan oleh Mahmudi (2010) bahwa efektivitas merupakan sejauh mana hasil produksi yang dikeluarkan mampu mencapai tujuan yang telah ditentukan oleh perusahaan. Efektivitas alokasi room allotment kepada biro perjalanan wisata dihitung menggunakan rumus: 
Denny Martin, Ida Ayu Sri Puspa Adi, Putu Ayu Aryasih

$$
\text { Persen efektivitas }=\frac{\text { Realisasi }}{\text { Target }} \times 100 \%
$$

Alat ukur yang digunakan sebagai pedoman dalam melihat efektivitas alokasi room allotment adalah :

$$
\begin{array}{ll}
\text { Lebih dari } 100 \% & =\text { Sangat Efektif } \\
85 \% \text { sampai } 99 \% & =\text { Efektif } \\
65 \% \text { sampai } 84 \% & =\text { Cukup Efektif } \\
\text { Kurang dari } 65 \% & =\text { Kurang Efektif }
\end{array}
$$

Efektivitas alokasi room allotment di Kaha Tours and Travel menunjukan bahwa pada tahun 2015 prosentase efektivitas tertinggi yaitu mencapai $121 \%$ sehingga dapat dikatakan sangat efektif dan tahun 2017 prosentase efektivitas terendah yaitu 42\% dengan nilai keterangan yaitu kurang efektif dan rata-rata dari tahun 2015 hingga 2019 persen efektivitas produksi room night dari target yang telah ditentukan berada pada angka 74\% yaitu cukup efektif.

Tabel 4: Efektivitas Room Allotment K. Tours and Travel 2015-2019

\begin{tabular}{lllll}
\hline No. & Tahun & Efektivitas & Kriteria & Keterangan \\
\hline 1. & 2015 & $121 \%$ & $>100 \%$ & Sangat Efektif \\
2. & 2016 & $61 \%$ & $65 \%-84 \%$ & Cukup Efektif \\
3. & 2017 & $42 \%$ & $<65 \%$ & Kurang Efektif \\
4. & 2018 & $87 \%$ & $85 \%-99 \%$ & Efektif \\
5. & 2019 & $59 \%$ & $<65 \%$ & Kurang Efektif \\
\hline
\end{tabular}

Biro perjalanan wisata M.A. menunjukkan kinerja yang berfariasi dalam pemanfaatan alokasi kamar yang telah diberikan oleh pihak hotel, sebagaimana bisa dilihat pada tabel 5 .

Tabel 5: Efektivitas Room Allotment G. Travel Associates 2015-2019

\begin{tabular}{lllll}
\hline No. & Tahun & Efektivitas & Kriteria & Keterangan \\
\hline 1. & 2015 & $11 \%$ & $<65 \%$ & Kurang Efektif \\
2. & 2016 & $66 \%$ & $65 \%-84 \%$ & Cukup Efektif \\
3. & 2017 & $121 \%$ & $>100 \%$ & Sangat Efektif \\
4. & 2018 & $147 \%$ & $>100 \%$ & Sangat Efektif \\
5. & 2019 & $131 \%$ & $>100 \%$ & Sangat Efektif \\
\hline & Total & $95 \%$ & $85 \%-99 \%$ & Efektif \\
\hline
\end{tabular}

Dari tahun 2017 sampai 2019 kriteria efektivitas lebih dari 100\% sehingga indikator penilaian menunjukan sangat efektif, produksi room night paling rendah terdapat pada tahun 2015 kriteria efektivitas 11\% dengan kriteria indikator menunjukan kurang efektif dan dengan rata-rata efektivitas produksi roo night dari target yang telah ditentukan dari tahun 2015-2019 adalah 95\% yaitu efektif.

Efektivitas alokasi room allotment di MG Holiday menunjukan prosentase fektivitas tertinggi pada tahun 2015 yaitu sebesar 73\% dengan katagori cukup efektif dan terendah pada tahun 2018 sebesar 38\% dengan katagori kurang efektif dan rata-rata efektivitas dari tahun 2015 hingga 2019 sebesar 58\% dengan katagori kurang efektif. Tabel 6 berikut memperlihatkan tingkat effektiwitas tersebut. 
Tabel 6: Efektivitas Room Allotment M.G.H. 2015-2019

[Sumber : The Kuta Beach Heritage Hotel (Data diolah), 2020]

\begin{tabular}{lllll}
\hline No. & Tahun & Efektivitas & Kriteria & Keterangan \\
\hline 1. & 2015 & $73 \%$ & $65 \%-84 \%$ & Cukup Efektif \\
2. & 2016 & $44 \%$ & $<65 \%$ & Kurang Efektif \\
3. & 2017 & $68 \%$ & $65 \%-84 \%$ & Cukup Efektif \\
4. & 2018 & $38 \%$ & $<65 \%$ & Kurang Efektif \\
5. & 2019 & $66 \%$ & $65 \%-84 \%$ & Cukup Efektif \\
\hline & Rata-rata & $58 \%$ & $<65 \%$ & Kurang Efektif \\
\hline
\end{tabular}
M.A.

Berikut merupakan efektivitas alokasi room allotment pada biro perjalanan wisata

Tabel 7: Efektivitas Room Allotment M.A. 2015-2019

[Sumber: The Kuta Beach Heritage Hotel (Data diolah), 2020]

\begin{tabular}{lllll}
\hline No. & Tahun & Efektivitas & Kriteria & Keterangan \\
\hline 1. & 2015 & $101 \%$ & $>100 \%$ & Sangat Efektif \\
2. & 2016 & $40 \%$ & $<65 \%$ & Kurang Efektif \\
3. & 2017 & $38 \%$ & $<65 \%$ & Kurang Efektif \\
4. & 2018 & $37 \%$ & $<65 \%$ & Kurang Efektif \\
5. & 2019 & $35 \%$ & $<65 \%$ & Kurang Efektif \\
\hline & Rata-rata & $50 \%$ & $<65 \%$ & Kurang Efektif \\
\hline
\end{tabular}

Tabel 7 menunjukan persen efektivitas tertinggi pada tahun 2015 yaitu 101\% dengan kriteria sangat efektif, sedangkan persen efektivitas terendah pada tahun 2019 yaitu sebesar 35\% dengan kriteria keterangan kurang efektif dan pada tahun 2016 hingga 2019 terjadi penurunan efektivitas dengan nilai di bawah 65\% sehingga membuat kriteria penilaian menjadi kurang efektif. Penilaian rata-rata dari tahun 2015 hingga 2019 menunjukan bahwa persen efektivitas di angka 50\% dengan kriteria penilaian kurang efektif.

Efektivitas alokasi room allotment di P.W. menunjukan tahun 2017 adalah peningkatan tertinggi yaitu dengan prosentase efektifitas mencapi 88\% dengan kategori penilaian efektif, Sedangkan nilai efektifitas terendah terdapat pada tahun 2015 yaitu 23\% dengan katagori kurang efektif, sedangkan rata-rata efektivitas selama 5 tahun yaitu sebesar $65 \%$ dengan katagori cukup efektif.

Tabel 8: Efektivitas Room Allotment P. W. 2015-2019

[Sumber : The Kuta Beach Heritage Hotel (Data diolah), 2020]

\begin{tabular}{lllll}
\hline No. & Tahun & Efektivitas & Kriteria & Keterangan \\
\hline 1. & 2015 & $23 \%$ & $<65 \%$ & Kurang Efektif \\
2. & 2016 & $81 \%$ & $65 \%-84 \%$ & Cukup Efektif \\
3. & 2017 & $88 \%$ & $85 \%-99 \%$ & Efektif \\
4. & 2018 & $73 \%$ & $65 \%-84 \%$ & Cukup Efektif \\
5. & 2019 & $63 \%$ & $<65 \%$ & Kurang Efektif \\
\hline & Rata-rata & $65 \%$ & $65 \%-84 \%$ & Cukup Efektif \\
\hline
\end{tabular}

Berikut merupakan efektivitas alokasi room allotment pada biro perjalanan wisata H. Tours and Travel menunjukan bahwa dari tahun 2015 hingga 2019 persentase 
Denny Martin, Ida Ayu Sri Puspa Adi, Putu Ayu Aryasih

efektifitas di bawah 65\% dengan prosentase efektivitas rata-rata selama 5 tahun yaitu $33 \%$ dengan produksi room night terendah terdapat pada tahun 2019 yaitu 26\% dengan kriteria keterangan kurang efektif dan produksi room night tertinggi pada tahun 2015 dengan kriteria keterangan kurang efektif. Berikut dapat dilihat pada Tabel 9.

Tabel 9. Efektivitas Room Allotment H. Tours \& Travel 2015-2019

[Sumber : The Kuta Beach Heritage Hotel (Data diolah), 2020]

\begin{tabular}{lllll}
\hline No. & Tahun & Efektivitas & Kriteria & Keterangan \\
\hline 1. & 2015 & $45 \%$ & $<65 \%$ & Kurang Efektif \\
2. & 2016 & $29 \%$ & $<65 \%$ & Kurang Efektif \\
3. & 2017 & $31 \%$ & $<65 \%$ & Kurang Efektif \\
4. & 2018 & $34 \%$ & $<65 \%$ & Kurang Efektif \\
5. & 2019 & $26 \%$ & $<65 \%$ & Kurang Efektif \\
\hline & Rata-rata & $33 \%$ & $<65 \%$ & Kurang Efektif \\
\hline
\end{tabular}

Efektivitas alokasi room allotment di Asia World menunjukan tahun 2016 merupakan tahun nilai produksi tertinggi dengan efektivitas mencapai 43\% dengan keterangan penilaian yaitu kurang efektif, sedangkan nilai produksi terendah terdapat pada tahun 2015 yaitu 0\% dan dari tahun 2015 hingga 2019 persen efektifitas di bawah $65 \%$ sehingga membuat kriteria penilaian menjadi kurang efektif sepanjang tahun. Dapat dilihat pada Tabel 10.

Tabel 10: Efektivitas Room Allotment A.W. 2015-2019

[Sumber : The Kuta Beach Heritage Hotel (Data diolah), 2020]

\begin{tabular}{|c|c|c|c|c|}
\hline No. & Tahun & Efektivitas & Kriteria & Keterangan \\
\hline 1. & 2015 & $0 \%$ & $<65 \%$ & Kurang Efektif \\
\hline 2. & 2016 & $43 \%$ & $<65 \%$ & Kurang Efektif \\
\hline 3. & 2017 & $26 \%$ & $<65 \%$ & Kurang Efektif \\
\hline 4. & 2018 & $24 \%$ & $<65 \%$ & Kurang Efektif \\
\hline \multirow[t]{2}{*}{5.} & 2019 & $8 \%$ & $<65 \%$ & Kurang Efektif \\
\hline & Rata-rata & $20 \%$ & $<65 \%$ & Kurang Efektif \\
\hline
\end{tabular}

Berikut merupakan efektivitas alokasi room allotment pada biro perjalanan wisata G.V. sebagaimana terdapat pada Tabel 11.

Tabel 11. Efektivitas Room Allotment BPW G. V. 2015-2019

Sumber: The Kuta Beach Heritage Hotel (Data diolah), 2020

\begin{tabular}{lllll}
\hline No. & Tahun & Efektivitas & Kriteria & Keterangan \\
\hline 1. & 2015 & $4 \%$ & $<65 \%$ & Kurang Efektif \\
2. & 2016 & $17 \%$ & $<65 \%$ & Kurang Efektif \\
3. & 2017 & $21 \%$ & $<65 \%$ & Kurang Efektif \\
4. & 2018 & $0 \%$ & $<65 \%$ & Kurang Efektif \\
5. & 2019 & $2 \%$ & $<65 \%$ & Kurang Efektif \\
\hline & Rata-rata & $8 \%$ & $<65 \%$ & Kurang Efektif \\
\hline
\end{tabular}

Pada Tabel 11 menunjukan bahwa efektivitas alokasi room allotment di G.V. menunjukan tahun 2017 dengan efektivitas sebesar 21\%, terendah pada tahun 2018 
dengan tidak memiliki produksi sama sekali, dan dari tahun 2015 hingga 2019 persen efektifitas di bawah 65\% sehingga membuat kriteria penilaian menjadi kurang efektif sepanjang tahun.

Dari data-data tersebut di atas dapat dirangkum effektifitas alokasi kamar yang diberikan kepada biro perjalanan. Berikut merupakan rata-rata efektivitas alokasi room allotment biro perjalanan wisata di hotel The Kuta Beach Heritage Bali tahun 2015-2019 pada Tabel 12.

Tabel 12: Efektivitas Room Allotment di Hotel The Kuta Beach Heritage Bali 2015-2019 [Sumber : The Kuta Beach Heritage Hotel (Data diolah), 2020]

\begin{tabular}{llccc}
\hline No. & Biro Perjalanan Wisata & Efektivitas & Kriteria & Keterangan \\
\hline 1. & K Tours \& Travel & $74 \%$ & $65 \%-84 \%$ & Cukup Efektif \\
2. & G Travel Association. & $95 \%$ & $85 \%-99 \%$ & Efektif \\
3. & M. G. H. & $58 \%$ & $<65 \%$ & Kurang Efektif \\
4. & M. A. & $50 \%$ & $<65 \%$ & Kurang Efektif \\
5. & P. W. & $65 \%$ & $65 \%-84 \%$ & Cukup Efektif \\
6. & H. Tours \& Travel. & $33 \%$ & $<65 \%$ & Kurang Efektif \\
7. & A.W. & $20 \%$ & $<65 \%$ & Kurang Efektif \\
8. & G. V. & $8 \%$ & $<65 \%$ & Kurang Efektif \\
\hline Rata-rata & $50 \%$ & $<65 \%$ & Kurang Efektif \\
\hline
\end{tabular}

Pada Tabel 12 menunjukan efektivitas selama 5 tahun pada 8 biro perjalanan wisata yang mempunyai kerjasama dengan hotel The Kuta Beach Heritage. K.Tours memiliki tingkat efektivitas rata-rata sebesar 74\% dengan kriteria penilaian cukup efektif. G. Travel Associates memiliki tingkat efektivitas rata-rata sebesar 95\% dengan kriteria penilaian efektif. M.G.H. memiliki tingkat efektivitas rata-rata sebesar $58 \%$ dengan kriteria penilaian kurang efektif. Mandira Abadi memiliki tingkat efektivitas rata-rata sebesar 50\% dengan kriteria penilaian kurang efektif. P. W. memiliki tingkat efektivitas rata-rata sebesar $65 \%$ dengan kriteria penilaian cukup efektif. H. Tours and Travel memiliki tingkat efektivitas rata-rata sebesar 33\% dengan kriteria penilaian kurang efektif. A. W. memiliki tingkat efektivitas rata-rata sebesar $20 \%$ dengan kriteria penilaian kurang efektif. G. V. memiliki tingkat efektivitas rata-rata sebesar 8\% dengan kriteria penilaian kurang efektif. Dari keseluruhan biro perjalanan di atas memiliki hasil efektivitas rata-rata yaitu sebesar $50 \%$ dengan kriteria penilaian yaitu kurang efektif.

\subsection{Pembahasan}

Berdasarkan hasil perhitungan efektivitas alokasi room allotment yang diberikan hotel The Kuta Beach Heritage Bali untuk biro perjalanan wisata diperoleh bahwa efektivitas selama 5 tahun pada 8 biro perjalanan wisata. K.Tours memiliki tingkat efektivitas rata-rata sebesar $74 \%$ dengan kategoti penilaian cukup efektif. G. Travel Associates memiliki tingkat efektivitas rata-rata sebesar 95\% dengan kategori penilaian efektif. M.G.H. memiliki tingkat efektivitas rata-rata sebesar 58\% dengan kategori penilaian kurang efektif. M.A. memiliki tingkat efektivitas rata-rata sebesar $50 \%$ dengan kategori penilaian kurang efektif. P.W. memiliki tingkat efektivitas rata-rata sebesar $65 \%$ dengan kategori penilaian cukup efektif. $\mathrm{H}$. Tours and Travel memiliki tingkat efektivitas rata-rata sebesar 33\% dengan kategori penilaian kurang efektif. A.W. memiliki tingkat efektivitas rata-rata sebesar $20 \%$ dengan kategori penilaian kurang efektif. G.V. memiliki tingkat efektivitas rata-rata sebesar 8\% dengan kategori penilaian kurang efektif. Dari keseluruhan biro perjalanan di atas memiliki hasil efektivitas rata-rata yaitu sebesar $50 \%$ dengan kategori penilaian yaitu kurang efektif. 
Denny Martin, Ida Ayu Sri Puspa Adi, Putu Ayu Aryasih

Hasil dari pengukuran efektivitas disebabkan perusahaan perhotelan terkait erat dengan bisnis lain dalam perjalanan dan industri pariwisata. Turisme dan industri perhotelan sangat mempengaruhi satu sama lain, yang dipertimbangkan oleh beberapa asosiasi pariwisata dan perhotelan dan para pemimpin industri menggabungkan industri perhotelan dan pariwisata sebagai satu industri besar. Kelompok industri ini disebut Perhotelan dan Jaringan Pariwisata, yang menunjukkan semua langsung dan tidak langsung hubungan antara semua komponen industri besar ini (Chon dan Maier, 2012).

Biro perjalanan adalah bisnis yang menggabungkan dua atau lebih layanan perjalanan, seperti akomodasi, transportasi, tamasya, katering dan hiburan dan menjualnya melalui agen perjalanan atau langsung ke konsumen akhir sebagai produk tunggal (Devaraja dan Deepak, 2014). Operator tur dan hotel memainkan peran paling penting dan penting dalam pariwisata, operasi bisnis, pemesanan kamar, operator tur dari hotel berdasarkan dua jenis kontrak, yang merupakan penjatahan dan kontrak komitmen (Devaraja dan Deepak, 2014).

Dalam industri perhotelan, indikator utama kesuksesan sangat tergantung pada tingkat hunian (Abdullah \& Haan, 2012). Ini diukur dengan jumlah kamar yang dipesan dibagi dengan jumlah kamar yang tersedia (Bardi, 2007). Ruangan Penjatahan mempengaruhi hunian kamar, namun kontribusi penjatahan kamar terhadap hunian kamar tidak terlalu banyak, hunian kamar tidak hanya dipengaruhi oleh alokasi kamar, fluktuasi hunian kamar di hotel juga dapat dipengaruhi oleh tinggi musim, musim sepi, musim puncak, grup, peringatan perjalanan dari berbagai negara dan banyak alasan lainnya (Abdullah \& Haan, 2012).

Berdasarkan hasil wawancara, dalam manajemen allotment yang dilakukan oleh The Kuta Beach Heritage Bali telah sesuai dengan teori yang disampaikan oleh Suarthana (1987:57) yang terdiri dari pengajuan permohonan allotment dari pihak biro perjalanan wisata yang akan bekerjasama. Pemohonan diterima dan dikonfirmasikan oleh bagian penjualan dan pemasaran, lalu dibuatkan perjanjian kerjasama. Data allotment diproses sesuai dengan prosedur penerimaan allotment. Hanya ada satu penambahan yaitu keputusan diambil setelah melalui corporate offie. Apabila corporate office menyetujui maka baru diadakan pertemuan untuk kesepakatan kerjasama. Adanya keputusan corporate office sama dengan penelitian yang dilakukan oleh Aryasih (2017) bagi hotel hotel yang merupakan Chain International seperti hotel Nikko Bali Resort \& Spa persetujuan pemberian allotment harus sesuai dengan persetujuan dari Corporate office. Pihak Corporate office akan memberikan rekomendasi kepada hotel apakah hotel harus menyetujui pemberian allotment tersebut ataupun tidak.

Dalam pemberian allotment yang dilakukan oleh pihak hotel berdasarkan hasil wawancara sesuai dengan Suarthana (1987:59) pertimbangan pemberian allotment adalah jumlah produksi pengisian kamar biro perjalanan wisata yang bersangkutan, sehingga lebih tinggi produksi lebih banyak allotment yang diberikan. Perjanjian harga, lebih murah harga kontrak lebih banyak allotment yang diberikan. Pembayaran, semakin lancar pembayaran yang dilakukan oleh pihak biro perjalanan maka akan dijadikan pertimbangan dalam memberikan allotment lebih banyak pada periode kontrak kerja berikutnya. Tingkat pembatalan, biasanya semakin kecil tingkat pembatalan seperti no show dalam penggunaan allotment, maka pihak hotel akan memeberikan allotment lebih banyak pada biro perjalanan bersangkutan.

Beberapa implikasi teoritis dan empiris yang perlu mendapatkan perhatian dari para manajer hotel dan operator tur adalah sebagai berikut: kontrak penjatahan adalah perjanjian antara operator tur dan hotel untuk pemesanan kamar hotel dengan waktu rilis tertentu, dan persentase materialisasi, pemenuhan kamar yang dipesan merupakan tanggung jawab operator tur, dengan penyelesaian secara deposit (Devaraja dan Deepak, 2014). Tugba et.al (2011) menyampaikan desain kontrak penjatahan hotel dapat diringkas sebagai berikut: (1) Ketidakpastian permintaan membuat desain penjatahan hotel lebih 
dengan kontrak yang specific menjadi sulit. (2) Ketika hotel melakukan investasi khusus dengan transaksi yang tinggi dan operator tur memiliki daya tawar tinggi, hotel-hotel sangat bergantung pada operator tur. Dalam situasi ini, operator tur membuat kontrak yang kurang lengkap untuk meningkatkan fleksibilitas untuk menyesuaikan perubahan keadaan lingkungan. (3) Ketika tingkat kepercayaan antara hotel dan operator tur meningkat, efek negatif dari ketidakpastian lingkungan dan investasi khusus transaksi pada kelengkapan kontrak berkurang karena kepercayaan meningkatkan berbagi informasi dan perilaku kooperatif antara mitra kontrak.

Manajemen penjatahan di hotel ini mulai dari perencanaan, pengorganisasian, penggerakkan, dan pengendalian telah diterapkan dengan cukup baik tetapi masih mengalami beberapa kendala. Perencanaan penjatahan kamar, masih ada kendala di awal yaitu bagaimana caranya bernegosiasi dengan agen perjalanan dan cara memenangkan negosiasi dengan mereka. Sampai sekarang, kontrak penjatahan masih fleksibel dan tidak ada kompensasi untuk agen perjalanan yang tidak dapat memenuhi penjatahan kamar. Rintangan itu terjadi dalam mengendalikan implementasi ruang penjatahan adalah bahwa tidak ada sistem khusus untuk mengontrol penjatahan kamar. Manajemen penjatahan kamar mempengaruhi peningkatan. Namun, hunian kamar di hotel ini belum maksimal. Strategi manajemen yang dilakukan oleh hotel mampu menangani semua masalah dan kendala yang terjadi dalam pelaksanaan peruntukan ruangan sehingga sampai sekarang penjatahan kamar masih dikelola dengan baik meskipun belum maksimal meningkatkan hunian kamar di hotel.

\section{KESIMPULAN}

K. Tours memiliki tingkat efektivitas rata-rata sebesar $74 \%$ dengan kriteria penilaian cukup efektif. G.Travel Associates memiliki tingkat efektivitas rata-rata sebesar 95\% dengan kriteria penilaian efektif. M.G.H. memiliki tingkat efektivitas rata-rata sebesar $58 \%$ dengan kriteria penilaian kurang efektif. M.A. memiliki tingkat efektivitas rata-rata sebesar 50\% dengan kriteria penilaian kurang efektif. P.W. memiliki tingkat efektivitas rata-rata sebesar $65 \%$ dengan kriteria penilaian cukup efektif. H.Tours and Travel memiliki tingkat efektivitas rata-rata sebesar 33\% dengan kriteria penilaian kurang efektif. A.W. memiliki tingkat efektivitas rata-rata sebesar $20 \%$ dengan kriteria penilaian kurang efektif. G. V. memiliki tingkat efektivitas rata-rata sebesar $8 \%$ dengan kriteria penilaian kurang efektif. Dari keseluruhan biro perjalanan di atas memiliki hasil efektivitas rata-rata yaitu sebesar 50\% dengan kriteria penilaian yaitu kurang efektif..

\section{DAFTAR PUSTAKA}

Aryasih, P.A. (2017) Efektifitas Penetapan Room Allotment Kepada Online Travel Agent Di Nikko Bali Resort And Spa. Jurnal Bisnis Hospitaliti 6 DOI:https://doi.org/10.52352/jbh.v6i1.105

Castellani, M. \& Mussoni, M. (2005) An Economic Analysis of the Tourism Contracts: Allotment and Free Sale. https://www.researchgate.net/profile/Maurizio-Mussoni2/publication/267991360

Elshaer, I. A. \& Ayad, T. H. (2017) Exploring the Relationship between Allotment and Commitment Contracts and the Performance of Hotels and Tour Operators in Egypt. International Journal of Heritage, Tourism and Hospitality 11 (1/2), 75-86.

Febriyana, G.M.S., Suprastayasa, I.G.N.A., \& Darmiati, N.M. (2020). Do Facilities Affect Tourists' Satisfaction at Natural Tourist Attraction? A Case at Tegenungan Waterfall in Bali. TRJ Tourism Research Journal, 4 (2) 104-112

Ferguson, M. \& Smith, S. (2014) The changing landscape of hotel revenue management and the role of the hotel revenue manager. Journal of Revenue and Pricing Management 13 (1) 224-232 
Denny Martin, Ida Ayu Sri Puspa Adi, Putu Ayu Aryasih

Hendriyati, L. (2019) Pengaruh Online Travel Agent Terhadap Pemesanan Kamar Di Hotel Mutiara Malioboro Yogyakarta. Media Wisata 17 (1) DOI: https://doi.org/10.36276/mws.v17i1.279

Melissa, Melissa (2014) Kegiatan marketing communications the kuta beach heritage hotel bali. Internship thesis, Universitas Multimedia Nusantara.

Rama, V. O. P., Astawa, I. K., Wendri, I. G. M., \& Mudana, I. G. (2019). Room Allotment Management to Increase Room Occupancy and its Implication to Hotel Management Strategy. Jurnal Bali Membangun Bali, 2(2), 75-82. https://doi.org/10.51172/jbmb.v2i2.41

Santi, R., \& Suastini, N.M. (2019) Analisis Strategi Harga Wholesale untuk Meningkatkan Pendapatan Kamar di Bvlgari Resort Bali. Jurnal Bisnis Hospitaliti 8 (1) DOI: https://doi.org/10.52352/jbh.v8i1.375

Sugiyono (2012). Metodelogi Penelitian Kuantitatif Kualitatif dan R\&D. Bandung:Alfa Beta

Tristian, A. (2016) Peranan marketing communications the kuta beach heritage hotel Bali. Internship thesis, Universitas Multimedia Nusantar 